\title{
Self-oscillation suppression when turning non- rigid shafts using spring tools and the spring headstock center
}

\author{
Valery Svinin ${ }^{1, *}$, Aleksey Samsonov ${ }^{2}$, Andrey Savilov ${ }^{1}$, and Aleksey Pyatykh ${ }^{1}$ \\ ${ }^{1}$ Irkutsk National Research Technical University, Institute of Aircraft Construction, Mechanical \\ Engineering and Transport, 664074, Russia \\ ${ }^{2}$ Zabaikalye State University, Department of Technology, Transport and Communication, 672039, \\ Russia
}

\begin{abstract}
One of the new but understudied self-oscillation elimination methods applied in metal cutting involves creation of an extra tangential oscillating circuit adjusted to resonance with the main normal circuit in the cutting zone. To assess the efficiency of the method, spring tool and driving dogs were developed. They were used in axial turning of non-rigid shafts. In comparison with standard tools fastened in the center, spring tools decrease the amplitude of self-oscillations by a mean of $90 \%$.
\end{abstract}

\section{Introduction}

One of the key machine building issues is elimination of self-oscillations in metal cutting. Traditional elimination methods, especially under low-rigidity of the technological system, do not deliver positive results. Therefore, development and analysis of new self-oscillation elimination methods are crucial tasks.

One of the promising methods was proposed by Professor M.E. Elyasberg [1]. The method has not been used yet due to insufficient studies on its peculiarities. The method involves creation of an extra tangential oscillating circuit which would be connected with the cutting zone. The weight and rigidity along the cutting speed for the extra circuit should be lower than the same parameters for the main oscillating circuit of the technological system. By adjusting the weight and rigidity of the extra circuit, resonance of its tangential oscillations with normal self-oscillations of the technological system is created. As a result, self-oscillations disappear, and the cutter generates extra oscillations along the cutting speed. These oscillations do not deteriorate the machined surface. The designs of toolholders of the wide necking tool and console boring bars were proposed for practical application of the method. The experiments proved that self-oscillations can be eliminated using these tools. Their main disadvantages are complex design and bulkiness. A simpler design of the axial turning tool was suggested in the patent [2]. Its performance was studied using a simulation method $[3,4]$. However, the main condition of the method developed by M.E-. Elyasberg (adjustment of extra circuit oscillations to resonance with bending shaft

${ }^{*}$ Corresponding author: $\underline{\text { svinin_vm@mail.ru }}$ 
self-oscillations) was neglected. As a result, potentials of the method have not been unveiled.

Experiments can help assess the degree of self-oscillation elimination (e.g., for axial turning of the long non-rigid shaft with a length of 10 diameters accompanied by intensive self-oscillation excitation) [5]. When finish turning, the stock removal rate is less than the tip radius. Therefore, the mean value of angle $\varphi$ does not exceed $45^{\circ}$ exciting selfoscillations.

The research aims to study self-oscillation elimination efficiency when finish turning non-rigid shafts using tools implementing the method suggested by M.E. Elyasberg. To this end, a spring straight turning tool and a spring front driving dog were developed.

\section{Equipment and research methods}

A screw-cutting lathe 16B25Psp was used for experiments. Workpieces of 23,3 mm in diameter and $430 \mathrm{~mm}$ in length made from 45 steel $(\mathrm{HB}=198 \ldots 200)$ were fastened in the centers. For dry machining, a CSDNN 2525M12 straight-turning tool equipped with a SNGN 120412 inserts of T5K10 hard material and a spring tool with the same edge geometry were used. A spring too is shown in Fig. 1. It is head 4 of the normal tool whose neck 5 is supported by thin elastic plates 1 and 2 . Between these plates, space plate 3 is located. It adjusts the frequency of natural vertical oscillations of the tool by varying the distance to the neck when releasing tool-holder screws.

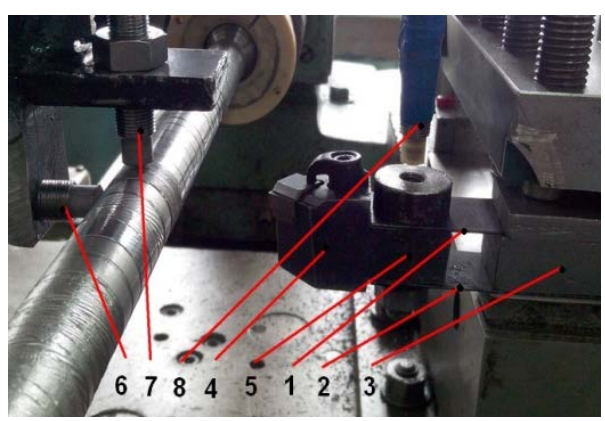

Fig. 1. Experimental machine for turning with a spring tool: 1,2 - elastic plates, 3 - space plate, 4 - cutter head, 5 - cutter neck, 6, 7, 8eddy current sensors

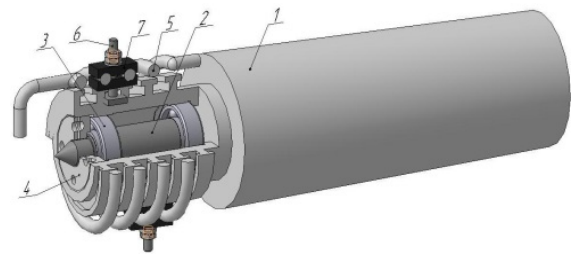

Fig. 2. Spring driving dog

The spring driving dog is shown in Figure 2. It consisits of frame 1 in which rotating center 2 is installed on two bearings 3. The external surface of the frame is Morse cone 6 . Loading in bearings is carried out by screw cap 4. Spring 5 transferring the cutting torque to the workpiece is located on the external cylindrical frame surface and supported by clamps 7. Clamps are connected with bolts 6 whose square heads are inserted in a screw T-slot on the cylindrical frame surface. The driving dog is installed in a conic spindle bore and fastened by a drawbar. Spring 5 rigidity is adjusted by moving clamps 7 along its turns. When machining, spring 5 creates torsion oscillations in the workpiece. Their frequency is adjusted to resonance with the frequency of eliminated bending self-oscillations. The experimental tool with a driving dog is shown in Figure 3.

To record horizontal and vertical workpiece oscillations and vertical spring tool head oscillations, eddy current sensors 6, 7,8 (see Fig. 1) supported by a bracket fastened to the screw cutting tailstock (see Fig. 3) were used. Sensor signals entered a PC passing through an ADC. Fourier analysis using Matlab helped determine the frequency spectrum of oscillations based on numerical data of each vibration record. Based on these data, 
diagrams of tool and workpiece movements in the plane normal to the cutting surface were created

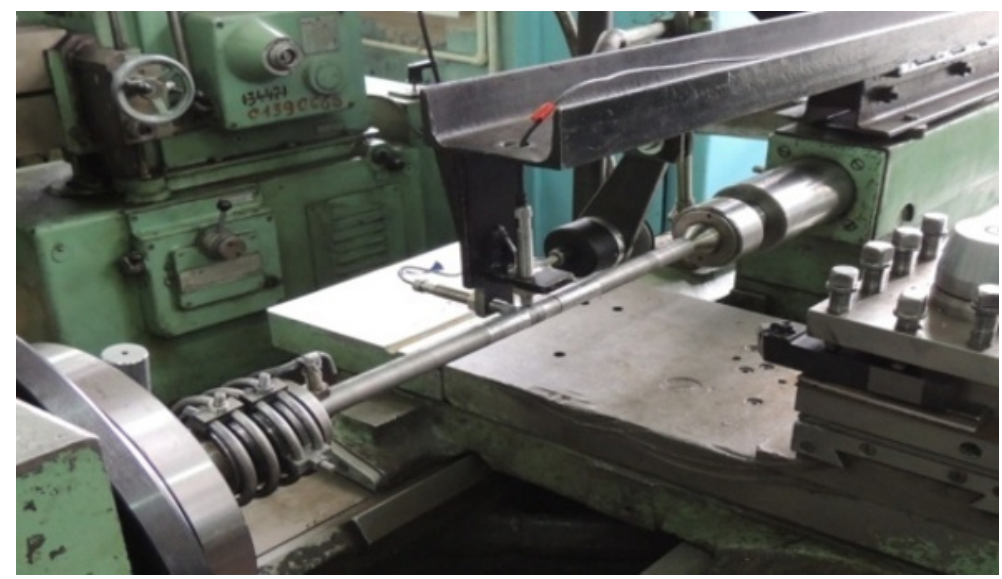

Fig. 3. Experimental machine for turning with a spring driving dog

When creating the diagrams, the sum of instantaneous values of vertical shifts of the workpiece and tool and current tool path were used as data for the horizontal axis. The current tool path is calculated by formula $S=t \times v$, where $t$ is current time $c ; v$ is cutting speed, $\mathrm{m} / \mathrm{sec}$. Current time was taken from the source data of vibration records. Cutting speed was calculated by instantaneous spindle rotation speed. Projections of instantaneous values $y$ of the amplitude of horizontal workpiece oscillations on the cutting surface normal were used as data for the vertical axis $A: A=y \times \sin 45^{\circ}$. When creating the diagrams of the first path of relative oscillations of the workpiece and tool, data obtained for one workpiece revolution were used. For the next paths, data obtained for the next workpiece revolutions were taken in to account. When creating every next path, data for the vertical axis were decreased by the thickness of cut: $a=f_{n} \times \sin 45^{\circ}$ where $f_{n}$ is feed per revolution, $m p r$.

To compare self-oscillation amplitudes when using rigid and spring tools, the first set of experiments was carried out. In the second set of experiments, the turning processes with rigid and spring driving dogs were compared. All the experiments were carried out under the following conditions: cutting depth was $a_{p}=0,25 \mathrm{~mm}$, feed was $f_{n}=0,095 \mathrm{~mm} / \mathrm{r}$, spindle speed $n$ was varying from 400 to $1000 \mathrm{rpm}$ in the first set and from 250 to $630 \mathrm{rpm}$ in the second one.

\section{Result and discussion}

The results of the first set of experiments on turning with rigid and spring tools are presented in Table 1. When using a rigid tool, intense self-oscillations are excited which is confirmed by the view of the machined surface and nature of the vibration records (Fig. 4) as well as the paths of oscillating movements of the workpiece relative to the tool (Fig. 5).

On the surface of the part, there are chatter marks which are intolerable for finish machining (see Fig. 4 and 5). With increase in the cutting velocity $v$ from 28 to $72 \mathrm{~m} / \mathrm{min}$ ( $n$ from 400 to $1000 \mathrm{rpm}$ ), the frequency of self-oscillations varies from 227 to $261 \mathrm{~Hz}$ (see Table 1). Its variation with increasing cutting velocity was observed by other researchers as well $[6 \ldots 8]$. 
Table 1.Workpiece oscillation parameters when machining with rigid and spring tools

\begin{tabular}{|c|c|c|c|c|c|c|c|c|c|}
\hline \multirow{3}{*}{$\begin{array}{l}\text { Rated } \\
\text { frequency } \\
\text { rotation n } \\
\text { rpm. }\end{array}$} & \multirow{3}{*}{$\begin{array}{l}\text { Actual } \\
\text { frequency } \\
\text { n, rotation } \\
\text { rpm.. }\end{array}$} & \multicolumn{3}{|c|}{ rigid tool } & \multicolumn{3}{|l|}{ spring tool } & \multirow{2}{*}{\multicolumn{2}{|c|}{$\begin{array}{ll}\text { Decrease in } & \text { the } \\
\text { amplitude } & \text { of } \\
\text { oscillations, \% }\end{array}$}} \\
\hline & & \multirow{2}{*}{$\begin{array}{l}\text { Frequency } \\
\text { 1, f, Hz }\end{array}$} & \multicolumn{2}{|l|}{$\begin{array}{l}\text { Amplitude } \\
\text { A, mkm }\end{array}$} & \multirow[t]{2}{*}{$\begin{array}{l}\text { Frequency } \\
\text { f, } \mathrm{Hz}\end{array}$} & \multicolumn{2}{|c|}{$\begin{array}{l}\text { Amplitude } \\
\text { A, mkm }\end{array}$} & & \\
\hline & & & $\begin{array}{l}\text { Horizon- } \\
\text { tal }\end{array}$ & $\begin{array}{l}\text { Verti- } \\
\text { cal }\end{array}$ & & $\begin{array}{l}\text { Horizon- } \\
\text { tal }\end{array}$ & $\begin{array}{l}\text { Verti- } \\
\text { cal }\end{array}$ & $\begin{array}{l}\text { Horizon- } \\
\text { tal }\end{array}$ & $\begin{array}{l}\text { Verti- } \\
\text { cal }\end{array}$ \\
\hline 400 & 414 & 241 & 23 & 52 & 233 & 2 & 5 & 91 & 90 \\
\hline 500 & 526 & 228 & 13 & 26 & - & - & - & - & - \\
\hline 630 & 654 & 259 & 96 & 161 & 227 & 10 & 20 & 90 & 88 \\
\hline 1000 & 1045 & 227 & 17 & 38 & 226 & 19 & 11 & +12 & 71 \\
\hline
\end{tabular}

The regular change in the self-oscillation amplitude with increasing cutting velocity (Fig. 6) is in good agreement with modern ideas of the self-oscillation regeneration mechanism [6...9]. Machining with a spring tool is smoother.
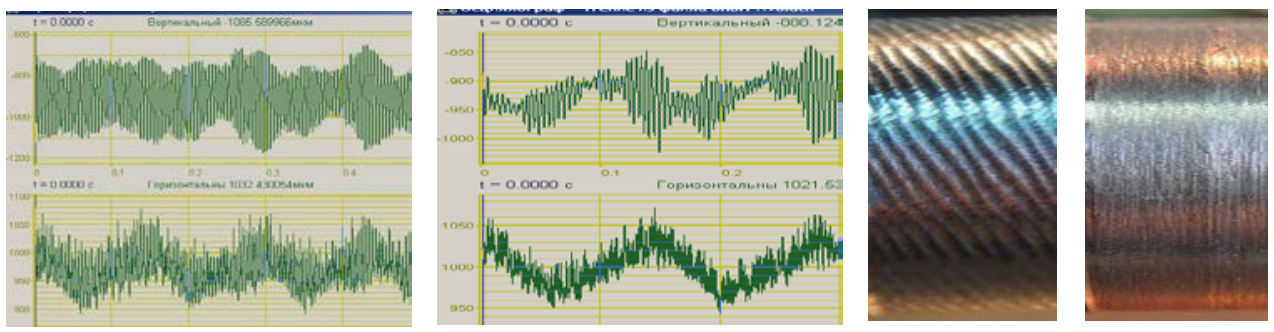

Fig. 4. Vibration records of vertical (at the top) and horizontal (at the bottom) workpiece oscillations and view of the surfaces machined with a rigid tool (left), with a spring tool (right); $n=400 \mathrm{rpm}$

Workpiece oscillations lost their self-excited nature (see Fig. 5), and chatter marks on the machined surface disappeared (see Fig. 4). Simultaneously recorded vibration patterns of the workpiece and the spring tool head show that the latter occur strictly in anti-phase to the vertical self-oscillations of the workpiece.

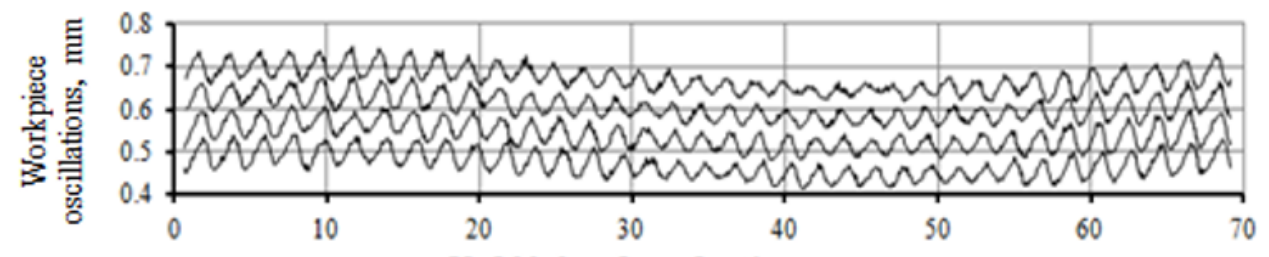

Unfolded surface of cutting, $\mathrm{mm}$

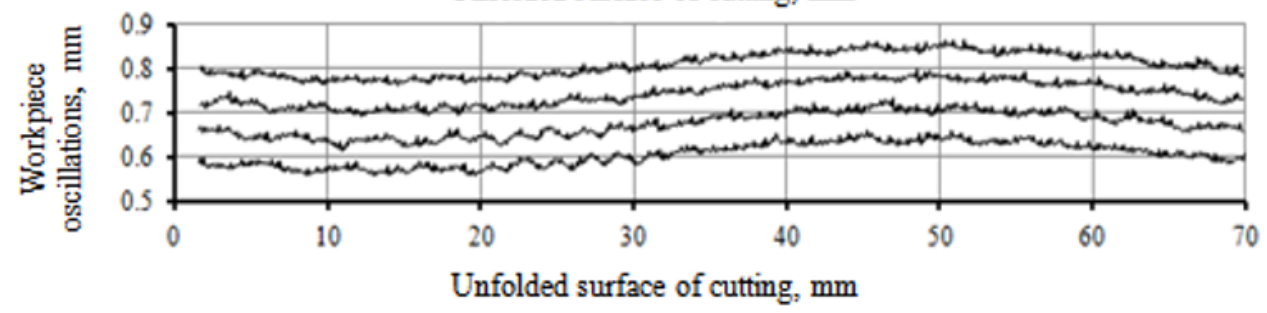

Fig. 5. Path of motions of the workpiece relative to the tool in a section perpendicular to the cutting surface when turning with rigid (at the top) and spring (at the bottom) tools: $n=400 \mathrm{rpm}$ 


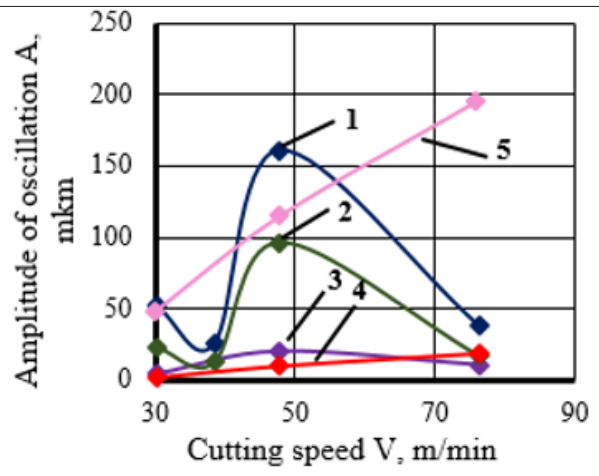

Fig. 6. Impact of cutting speed on amplitudes of vertical $(1,3)$ and horizontal $(2,4)$ selfoscillations of the workpiece when turning with rigid $(1,2)$ and spring $(3,4)$ tools and amplitudes of vertical (5) oscillations of the spring tool
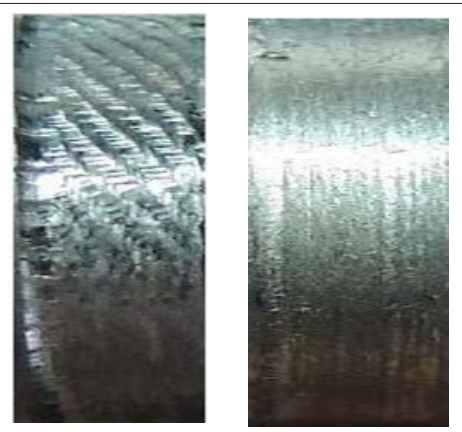

Fig. 7. View of the surfaces when turning with rigid (left) and spring (right) driving dogs; $n=400 \mathrm{rpm}$

Table 2. Workpiece oscillation parameters when machining with rigid and spring driving dogs

\begin{tabular}{|c|c|c|c|c|c|c|c|c|c|}
\hline \multirow{4}{*}{\begin{tabular}{|l} 
Rated \\
frequency \\
rotation n, \\
rpm.
\end{tabular}} & \multirow{4}{*}{$\begin{array}{l}\text { Actual } \\
\text { frequency } \\
\text { rotation n, } \\
\text { rpm.. }\end{array}$} & \multicolumn{6}{|c|}{ Parameters of workpiece oscillations during machining } & \multirow{3}{*}{\multicolumn{2}{|c|}{$\begin{array}{l}\text { Decrease in the } \\
\text { amplitude } \\
\text { oscillations, \% }\end{array}$}} \\
\hline & & \multirow{2}{*}{\multicolumn{3}{|c|}{\begin{tabular}{|l|l|} 
with a rigid dog \\
Frequenc & Amplitude \\
y & A, mkm
\end{tabular}}} & \multicolumn{3}{|c|}{ with spring driving dogs } & & \\
\hline & & & & & \multicolumn{3}{|c|}{\begin{tabular}{l|l} 
Frequenc & Amplitude \\
$\mathrm{y}$ & $\mathrm{A}, \mathrm{mkm}$
\end{tabular}} & & \\
\hline & & $\mathrm{f}, \mathrm{Hz}$ & \begin{tabular}{|l} 
Horizont \\
al
\end{tabular} & Vertical & $\mathrm{f}, \mathrm{Hz}$ & \begin{tabular}{|l} 
Horizont \\
al
\end{tabular} & Vertical & $\begin{array}{l}\text { Horizont } \\
\text { al }\end{array}$ & Vertical \\
\hline 250 & 263 & 194 & 10 & 42 & 197 & 5,8 & 25,5 & 42 & 39 \\
\hline 315 & 334 & 194 & 26 & 142 & 196 & 6,5 & 5,8 & 75 & 95 \\
\hline 400 & 414 & 193 & 59 & 277 & 194 & 3,5 & 19 & 94 & 93 \\
\hline 500 & 526 & 200 & 46 & 200 & 198 & 5,5 & 8,4 & 88 & 56 \\
\hline 630 & 654 & 195 & 62 & 214 & 194 & 3,6 & 4,9 & 94 & 97 \\
\hline
\end{tabular}

Therefore, they can be considered forced under the resonant mode. With increasing cutting velocity, the tool head oscillations increase, and the amplitude of the workpiece oscillations vary (see Fig. 6). It can be concluded that application of the spring tool instead of the rigid one decreases the intensity of workpiece oscillations by a mean of $90 \%$ (see Table 1).

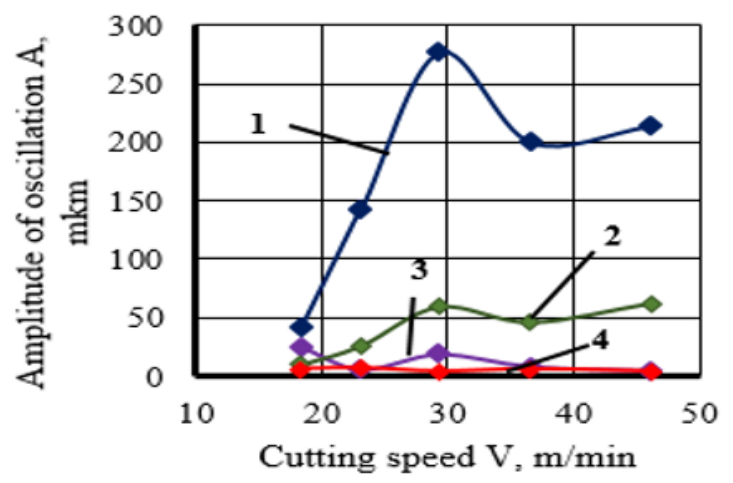

Fig. 8. Impact of the cutting speed on the amplitude of vertical $(1,3)$ and horizontal $(2,4)$ selfoscillations of the workpiece when turning with rigid $(1,2)$ and spring $(3,4)$ driving dogs 
The second set of experiments on using a driving dog with adjustable torsion rigidity is presented in Table 2 and in Figure 7. In the first half of the experiments, the maximum rigid driving dog was used. In the second half of the experiments, driving dog rigidity ensured the frequency of torsion oscillations of the workpiece equal to the frequency of eliminated bending self-oscillations. Figure 8 shows the effect of cutting velocity on workpiece oscillation amplitudes. The self-oscillation elimination effect using a spring driving dog was similar to the one using a spring tool.

Frequencies of natural oscillations of spring tools and driving dogs were adjusted with an error of $1 \ldots 2 \mathrm{~Hz}$ to resonance with the workpiece self-oscillation frequency when turning with a non-rigid tool under the same conditions. Due to the imperfect design of experimental tools, the adjustment process was more labor intensive.

\section{Conclusion}

The experiments with spring tools proved that creation of an extra oscillating circuit in the technological system is rather promising for ensuring the dynamic stability of the cutting process, especially under low rigidity of equipment or workpieces. It sets a task to create new progressive designs of tools and technological systems for eliminating self-oscillations in machining. Self-oscillation elimination methods can improve performance and quality of parts. Special attention should be paid to the adjustability of extra circuit oscillation frequencies. It is crucial for successful practical application of spring tools.

\section{References}

1. M.E. Elyansberg, V.A. Demchenko, I.A. Savinov, Vibration stability improvement method in metal cutting, Lathes and tooling, 4, 3-7, (1983)

2. D.A. Rastorguev, O.A. Rastorgueva, O.I. Drachev, S.V. Nikolaev, A tool for vibration cutting: patent 2292990 RF: MPK B23B 27/00, (2007)

3. D.A. Rastorguev, A.N. Shevchuk, Adjustment of the tool subsystem when machining non-rigid axisymmetric parts, Technical sciences-from theory to practice, 19, 47-55, (2013)

4. D.A. Rastorguev, A.N. Shevchuk, Impact of tool subsystem parameters on turning performance, Technical sciences-from theory to practice, 23, 45-52, (2013)

5. G. Stepan, A.K. Kiss, B. Ghalamchi, J. Sopanen, D. Bachrathy, Chatter avoidance in cutting highly flexible workpieces, CIRP Annals - Manufacturing Technology, 66, 377-380, (2017)

6. H.E. Merritt, Theory of Self-Excited Machine Tool Chatter, ASME J. Eng. Indus.,87, $447-454,(1965)$

7. H. Ota, K. Kono, On Chatter Vibrations of Machine Tool or Work Due to Regenerative Effect and Time Lag, ASME J. Eng. Indus., 96, № 4, 1337-1346, (1974)

8. V.P. Vogler, R.E. De Vor, S.G. Kapoor, Nonlinear Influence of Effective Lead Angle in Turning Process Stability, ASME J. Manuf. Sci. Eng., 124, 473-475, (2002)

9. V.M. Svinin, Self-arrangement of secondary self-oscillations while edge-cutting machining, STIN,1, 7-13,(2006) 